\title{
Dynamics Analysis Model of Nature Tourism System Development In Bogani Nani Wartabone National Park of Gorontalo Province
}

\author{
Irwan Bempah', Syamsu Qamar Badu', Bambang Suharto ${ }^{3}$ \\ ${ }^{1}$ Faculty of Agriculture, UniversitasNegeri Gorontalo
}

\begin{abstract}
In general, the interacting elements in the nature tourism system in NaniWartaboneBogani National Park (TNBNW) are population; some tourist visitors; community income; income tax; land use/forest cover and development policy direction. Simulation results show the population is predicted to increase until reaching 380,357 people in 2030. In the optimistic scenario, the population in 2013 is predicted as many as 158,195 people and will increase to 308,149 in 2030 . In the optimistic scenario of the number of tourists in 2013 predicted as many as 25,806 people and will increase to 145,215 people by 2030. Community income in 2008 of $\mathrm{Rp} \mathrm{12,000,000} \mathrm{is} \mathrm{expected} \mathrm{to}$ increase to $\mathrm{Rp} 78,806,894$ in 2030. Optimistic scenario of community revenues in 2013 is estimated at $\mathrm{Rp} 69,656,421$ will increase to $\mathrm{Rp} 484,520.719$ in 2030 . In an optimistic scenario subsidy in 2013 is estimated at $\mathrm{Rp} 22,107,690$ and will increase to $\mathrm{Rp}$ $175,305,853$ in 2030 . The optimistic scenario of primary forest cover in 2013 is estimated to cover 136,040 ha and will decrease slightly to 134,910 ha in 2030.
\end{abstract}

Keywords: Policy Model, System Dynamics, Nature tourism

\section{INTRODUCTION}

The system is a cluster or set of interrelated and organized components to achieve a specific goal or cluster of goals (Hartrisari, 2007). The system according to Gordon (1989) in Marimin, (2008), is seen as an aggregation or collection of related objects in harmonious interaction and interdependencies.From the objectives to be achieved, the system is a collection of elements that are in a state of interconnected for the same purpose. To support Hartrisari and Gordon's opinion, Purnomo (2012), conveyed that the system as a dynamic like models consisting of a network of variables that change over time. In recent developments, system theory ideas are used in the sciences of complexity that studies the self-organization and heterogeneous networks of interacting actors, and thermodynamic domains far from the equilibrium, the dynamics of chaotic, artificial life, artificial intelligence, and neural networks. Meanwhile, system analysis is an application of system principles to help decision making.Based on several theories above, the system can be used as a supporter in the decision-making process for a policy. Even some experts think the system approach can be used in policy analysis methods.

Historically, policy analysis has a disadvantage in basing its methodology to study social systems as a whole. As a reason, policy analysis has had little effect in predicting or solving social problems such as poverty, riots, racial intolerance, and pollution. It is because there is no comprehensive system research methodology in which the components cannotbe separated. A complex system cannotbe simplified into the sum of its parts (Allen, 1978 in Marimin, 2008).

In the context of nature tourism policy research in NaniWartaboneBogani National Park (TNBNW), Allen's theory is very relevant to be used as a basis for consideration by 
using system analysis method. The system can guide the understanding of the complexity of social problems that plague the needs of society and the sustainability of the region. Another consideration is the use of system performance, will be able to reduce some solutions that cannotbe applied in the real world. Dodds and Butler (2010), provides an overview of how tourism development policy by identifying the complexity of the factors impeding policy implementation. First, the success of the policyis determined by many components that act as sub-systems. The interaction between sub-systems can influence each other to achieve common goals. Second, connected interactions indicate the dynamic nature of the established system. Therefore, the nature and behavior of elements in the system also determine whether nature tourism development policies in conserved areas can be implementedalong with the objectives of the policy program.

The model is a simplification of a very complex system. Complexity means to describe that there are many components related to each other that they will be hard to separate. The more complex something, the higher the level of interrelationship with each other, especially the feedback processes of the system, as well as the number of components (Purnomo, 2012). Thus the preparation of the model will be able to describe all processes that occur within the system.

While the system approach is an organizational analysis approach that uses the characteristics of the system as the starting point of analysis as a scientific system in management. Starting from this concept of system analysis motion according to Marimin (2008), through six stages of analysis include; needs analysis, system identification, problem formulation, the establishment of system alternatives, determination of physical, socio-political realization and monitoring of economic and financial feasibility.

In contrast to Marimin (2008), Maani and Cavana (2007), introduced modeling of system and modeling methods through five stages: phase mapping problem; stage of building a causal loop model; dynamic modeling stage; stage of planning and modeling scenarios; and last is the implementation and learning of the organization. The last submitted method will be used as a reference in research on nature tourism development policyin a conservation area.

\section{RESEARCH METHOD}

The study was conducted in TNBNW from December 2013 to March 2014. Secondary data were collected by observation and document search techniques.

The types and sources of data referenced in this research are:

1. Primary data is data obtained directly in the field through the interview. The type of data that is taken directly is the identification of stakeholders' needs through the Focus Group Discussion (FGD)

2. Secondary Data is data obtained from various agencies or related institutions relevant to this research include:

a. Population demographic data

b. Data regardingnature tourism facilities

c. Data and information of NaniWartaboneBogani National Park (TNBNW), Provincial and District Forestry Office.

d. Data regarding forest cover

Methods of data collection in this study were conducted in the following way: 
a. Survey method, i.e., data collection was conducted through field observation and interview Focus Group Discussion (FGD)

b. Desk study method, which is collecting data and information through library search and document related research. as follows:

Building a dynamics model system is conducted with several stages of data analysis

1) Identify the definition of problems and needs. This information is used to generate behavior and to show changes of essential variables over time (Sunkar, 2008)

2) Based on the information gathered, the dynamic hypothesis will be formulated to explain the reasons behind the change based on the feedback principle. It is presented as a causal feedback loop that shows the association of various variables to form a closed loop.All the dynamics arise from the interaction of self-correcting (negative) self-reinforcing loops (positive). Since the input is the focal point of the dynamics system, causal pie diagrams are generated for each sub-system problem to show the relationship between the interconnection parameters in the sub-system.

3) Create an experiment based on parameters in the model to see changes in system behavior over time

4) Simulation is the only practical way to test conceptual models (Sterman, 2000, Sunkar, 2008)

5) Perform sensitivity analysis. It aims to know the sensitivity to the resistance of each parameter. Sensitive parameters are considered as potential indicators for the development of nature tourism resources in TNBNW (Sunkar, 2008)

\section{RESULT AND DISCUSSION}

The formulation of the problem is the activity of the system studied. Regarding, the development of nature tourism, the problem of the system is a gap between the needs of the subject and the existing conditions. Thus, the formulation of system problems is a condition of non-fulfillment of the needs of the subject in the real conditions that occur. The needs of the activists for the success of the development of nature tourism are the satisfaction of the needs of each stakeholder, while the current conditions cannot meet the needs of the subject.

The problems that arise need to get the attention of the government and the broader community. Alsoto the same coordination and understanding among stakeholders. A conflict of interest among stakeholders is a problem that requires a solution for the system to work constructively to achieve its objectives. Based on the analysis of stakeholders needs, the description of the problems in the system of development of nature tourism policy is presented in the form of causal loop diagram (causal loop). The condition of the system shows the causal relationship of various main parameters in the development of nature tourism. Population growth became one of the main parameters of this model. Population growth can lead to changes in land cover. It could also have an impact on the declining conservation of the conservation area that became the tourist attraction. Population growth can also encourage an increase in the number of tourists who have an impact on increasing government revenues and community-related tourism activities. This revenue increase could encourage the government to issue policies that could support tourism and conservation activities in the region. One of them is by increasing the 
sustainability of the area through the control of land cover. The preservation of protected forest ecosystems can be an attraction for visitors who come to the area of tourism in the area of TNBNW.

Based on the description above, structurally, the interacting elements in the nature tourism system, in general,are the population; some tourist visitors; community income; income tax; land use/forest cover and development policy direction. Interaction system as shown in Figure 2 below.

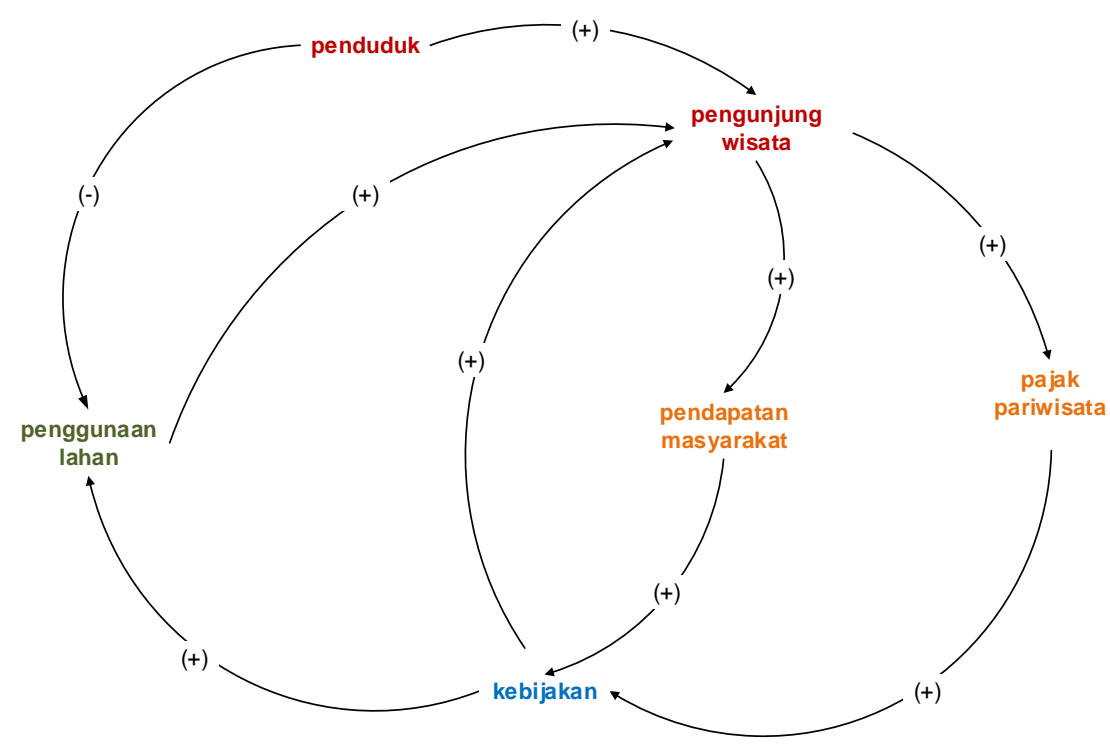

Figure 1Causal Loop Nature tourism Development in TNBNW

Technically, the causal loop is translated into a stock-flow diagram (SFD). Furthermore, the formulation of the flow of energy and information in SFD using a mathematical approach. The mathematicalapproachis based on secondary data, empirical data, and previous analysis results. Itis processed with Powersim Studio 2005E software.

\section{Sub-Model Identification}

Socioeconomic Sub-Model. Figure 3. Shows the socioeconomic sub-model consists of the main parameters in the form of the population that influences the number of tourists visiting the conservation area. Increasing tourists will foster tax increases from the tourism sector for local governments. In addition, the existence of tourists can encourage the increaseincommunity income from tourism activities. 


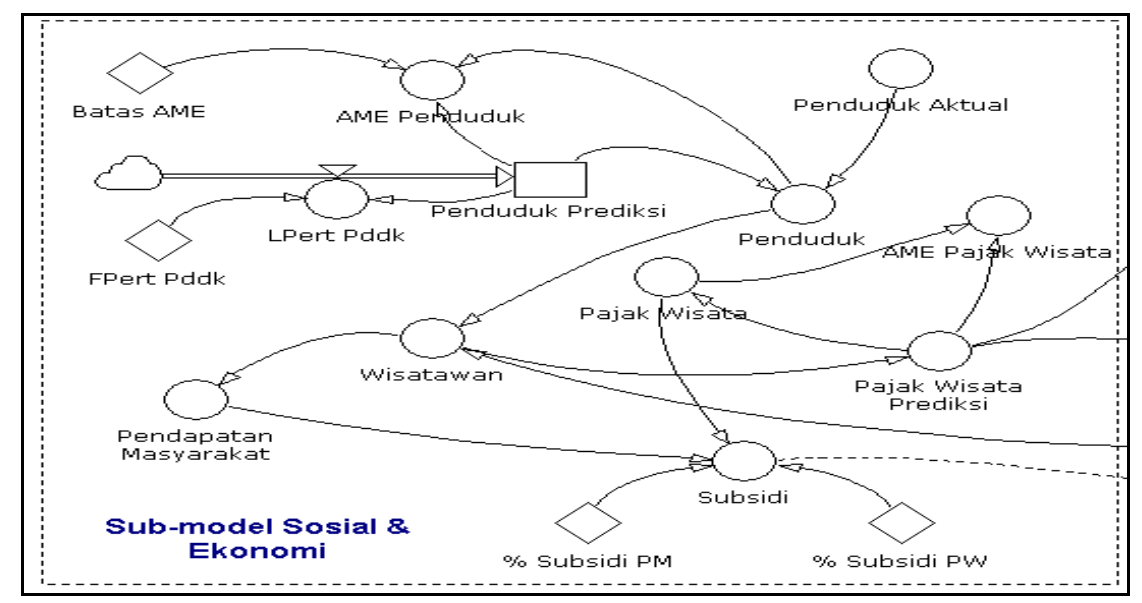

Figure 2. Socioeconomic Sub-Model

Policy and Environment Sub-Model. Policy and environment sub-model consists of the main parameters affecting changes in land cover and number of tourist visits. Land use change is illustrated by changing the extent of various land cover. The land cover classification consists ofthe primary dry-land forest; secondary dry-land forest; agriculture consisting of plantations, dry-land farming, and rice fields; shrubs; as well as another land cover (cloud cover, settlement, open land, empty land).

Figure 3Policy and Environment Sub-Modelshowsthatthere is an increase in primary forest cover of primary dry-land from 2008 to 2012, which is about $16.0 \%$ per year. Meanwhile, secondary dry-land forests have decreased by about $24 \%$ per year. This decrease is estimated due to part of secondary dry-land forest transformed into primary dry-land and shrubs. An increase in land cover of shrub occurs about $0.26 \%$ per year. Itis used as the basis for formulating the model and simulating the dynamics of land cover in 2013 until 2030.

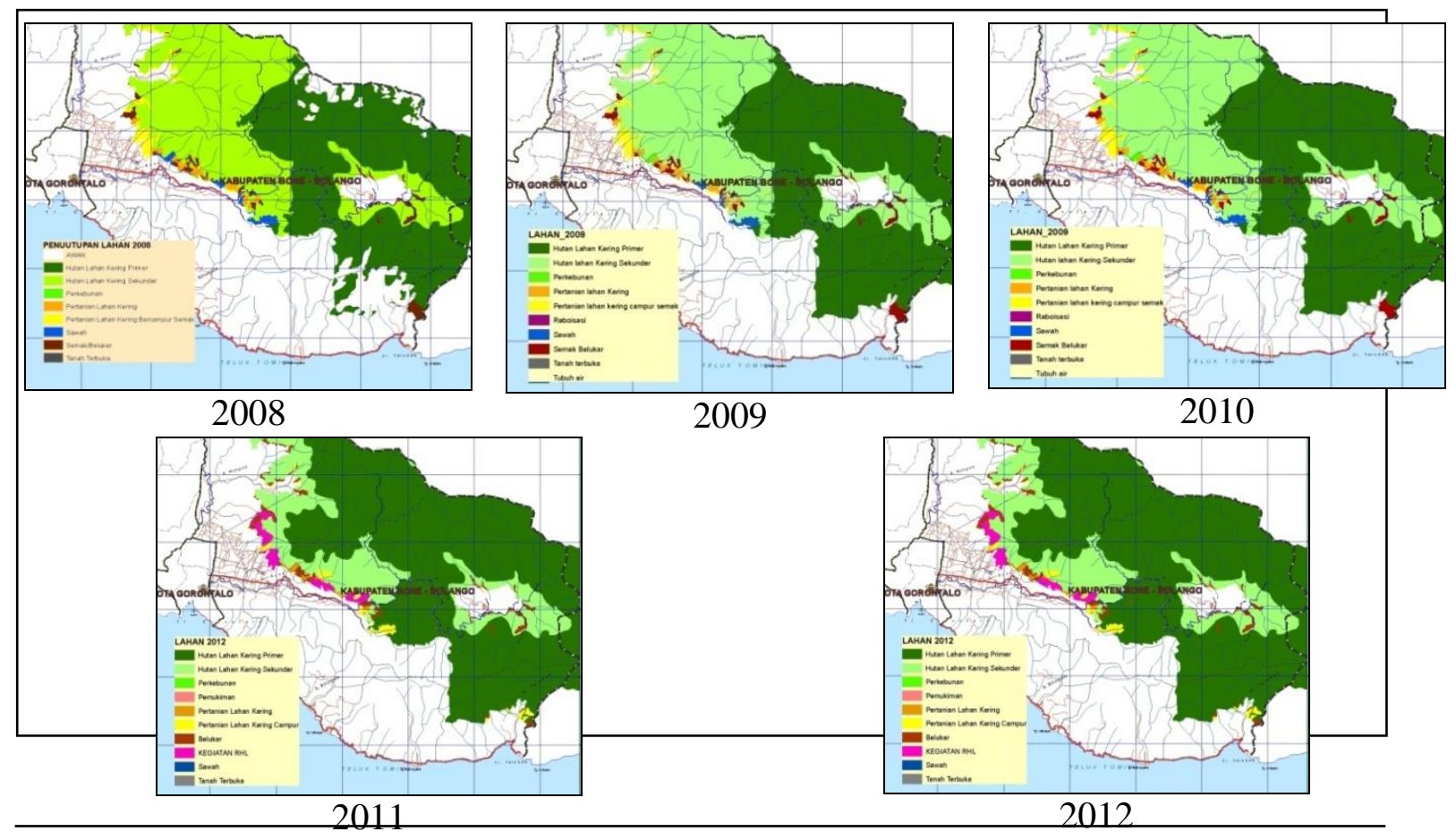

Jurnal Manajemen/Volume XXII, No. 02, Juni 2018: 251-263 


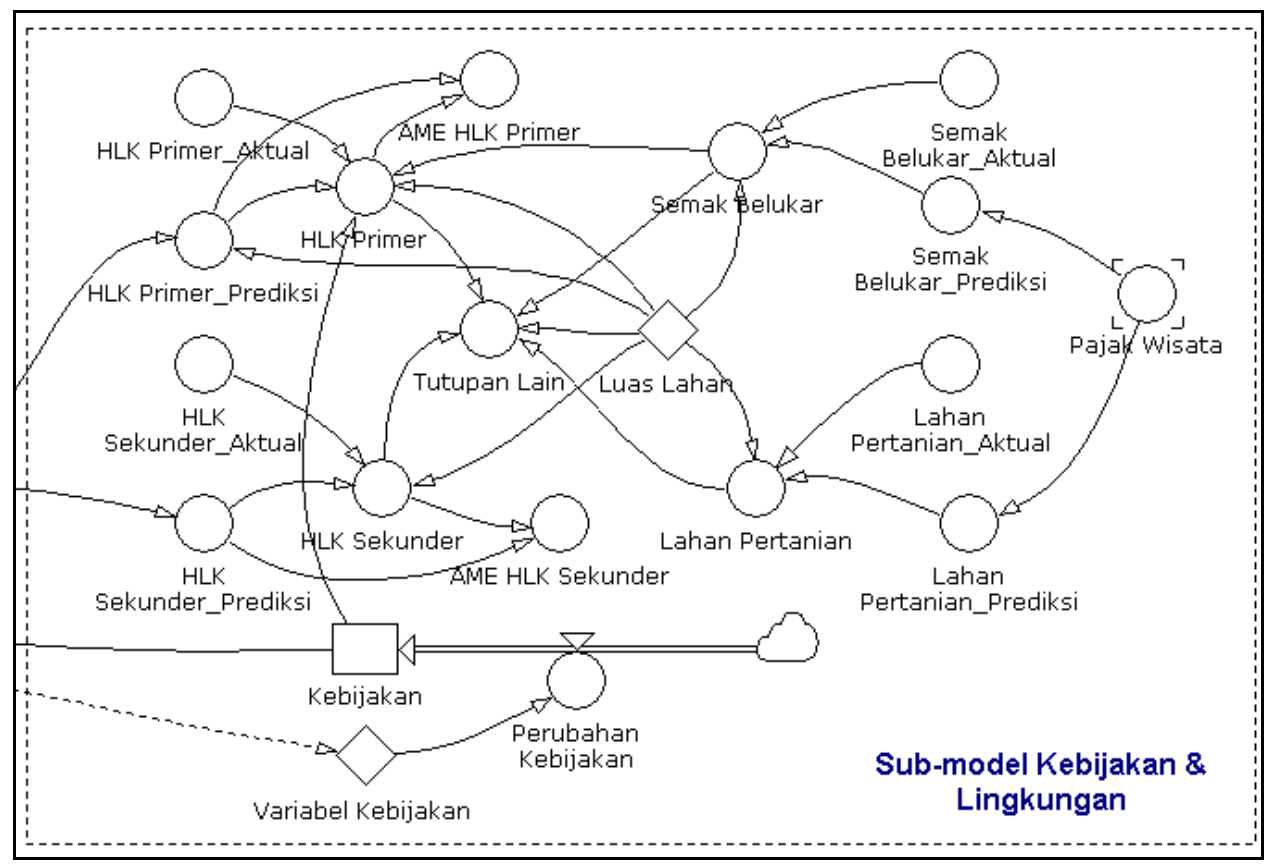

Figure 4. Policy and Environment Sub-Model

\section{Model Simulation}

Socioeconomic Model Simulation. Socioeconomic sub-model is seen from population and income in TNBNW Bone Bolango Regency, Gorontalo Province. The population has a positive linear line in time. The pattern is similar to the pattern of unemployment graph. These conditions provide information that the population growth, followed by the increase of visitors in the natural tourist area lombongo.

The simulation results show that the population growth rate from 2008 to 2012 is quite large, at $5.0 \%$ per year while the growth of tourist numbers has a positive correlation with proportional population growth.Itis used as a basis for developing models and simulating population growth and tourist numbers in 2013 until 2030. The socioeconomic sub-model simulation results show that population growth is increasing over time. The trend of population growth and the number of positive travelers follow the exponential curve in 2013 until 2030. The simulated results of population and tourist growth are shown in Figure 6. 


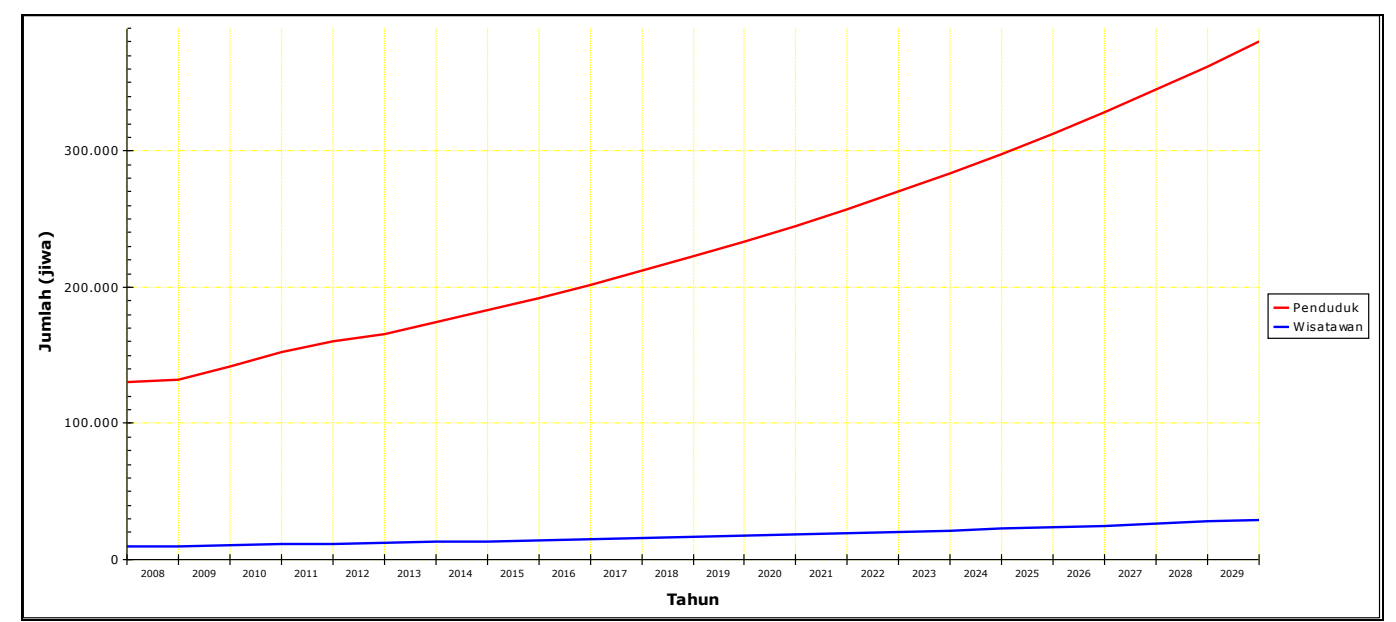

Figure 5. The simulation results of population growth and the number of tourists around TNBNW Bone Bolango.

Figure 6 shows population growth and the number of tourists will continue to increase from 2013 to 2030 . The population in 2008 is expected to increasefrom 130,025 people to 165,949 in 2013 . The population is expected to increaseto 380,357 by 2030 . It will lead to an increase in the number of tourist visits to conservation areas. The number of tourists is expected to increase from 12,031 visitors in 2013 to 27,576 in 2030.

The number of tourist visits is predicted to increase the income of local people who are engaged in nature tourism field. In addition, the number of tourist visits will also increase the tourism tax for the government. Both of these can be shared for subsidies for the improvement of tourism facilities and infrastructure in conservation areas. These conditions could have an impact on the increase in the number of tourist visits. Nevertheless, the subsidy until 2012 is still not set aside. The results of the simulation of community income and tourism taxes are presented in Figure 7.

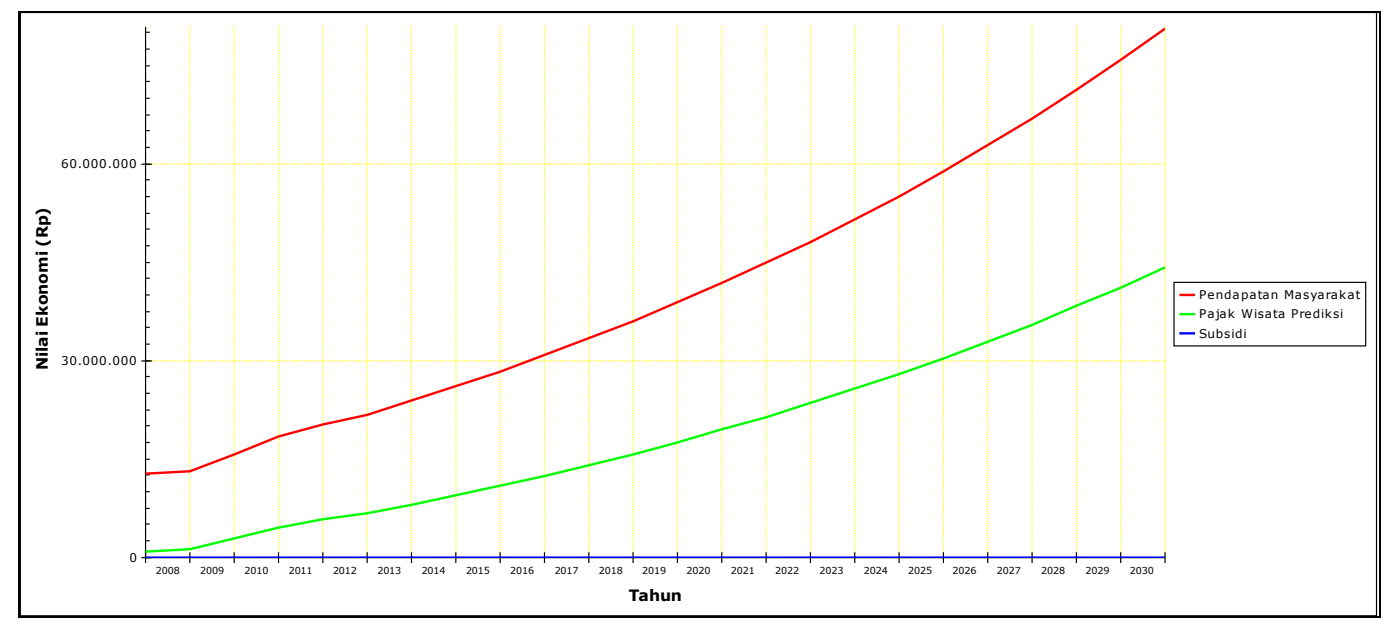

Figure 6. The simulation result of community income and nature tourism taxes

The simulation results show that community income and tourism taxes will continue to increase from 2013 to 2030 . Revenue is expected to increase from Rp $12,000,000$ in 2008 to $\mathrm{Rp} 75,806,895$ in 2030 , while the original tourism tax of $\mathrm{Rp}$ $1,250,000$ in 2008 is expected to increase to Rp 41,177,099 in 2030. 
Policy and Environment Simulation. The simulation results in Figure 65 show the tendency of increasing primary dry-land forest cover and shrubs. While in secondary forest land cover and agricultural land (plantation, rice field, and dry-land farming), there is a tendency to decrease the area of land cover. The trend predicts the area of primary dryland forest cover would increase from 49,561 ha in 2008 to 131,934 ha in 2030.

Meanwhile, a portion of the area of secondary forest land cover will turn into primary dry land and shrubs.It resulted in the area of secondary dry-land forest cover estimated to shrink from 47,445 ha in 2008 to 2,328 ha alone in 2016. If this continues to be allowed, then it is predicted that by 2017 onwards the cover of the secondary dry-land forest is already transformed into the primary dry-land forest and some shrubs.

The same thing happened in the area of an agricultural land cover consisting of dry farmland, plantation and rice field. If we looked at the shrinking agricultural land area of 1,787 ha in 2008 to 482 ha in 2012, it is predicted that agricultural land will also change to other cover since 2014. The dynamics of this land cover is still represented by several types of land cover resulting from satellite image interpretation which has relatively no dominant area. Different types of land cover include cloud cover, settlement, reforestation, open land, and empty land made in one class as another land cover.

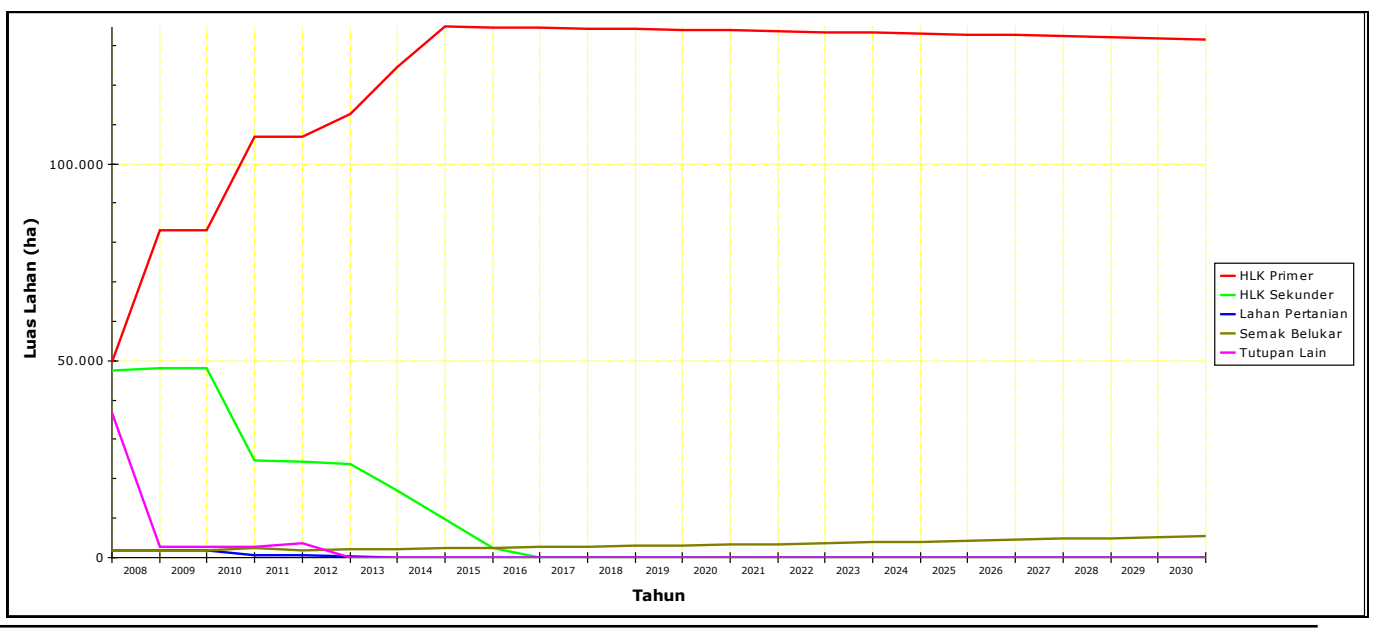

Figure 7 Simulation results of forest and land cover in TNBNW area

Model Scenario. The policy scenario is structured based on changes in key variables in the model that are in line with various government policies on the environment, forestry,and tourism. Each scenario will intervene in the model to obtain results by predetermined policies. The scenario consists of the existing condition (business as usual, $\mathrm{BAU}$ ), pessimistic scenario, moderate scenario and optimistic scenario (Table 3).

Table 1. Scenario intervention model parameters

\begin{tabular}{lclcl}
\hline \multirow{2}{*}{ Parameter } & Condition & \multicolumn{3}{c}{ Scenario } \\
\cline { 3 - 5 } & Existing & Pessimisti & Moderate & Optimistic \\
& & c & & \\
\hline Population growth & $5,0 \%$ & $5,5 \%$ & $4,5 \%$ & $4,0 \%$ \\
Policy Variables & existing & less good & good & good
\end{tabular}




\begin{tabular}{lrrrr} 
& \multicolumn{3}{c}{ enough } \\
Community $\quad$ income & $0,0 \%$ & $0,0 \%$ & $1,0 \%$ & $5,0 \%$ \\
subsidies & $0,0 \%$ & $0,0 \%$ & $25,0 \%$ & $50,0 \%$ \\
Tourism tax subsidies & $0,0 \%$ & \\
\hline
\end{tabular}

Based on the data obtained, the population growth rate is about $5 \%$ per year. While the policy according to the current conditions (existing) is assumed not yet to develop new policies. In addition, it is assumed that the public and the government have not set aside a portion of revenue and tourist tax for tourism development (0\%).

The pessimistic scenario is prepared with predicted population growth to increase (5.5\%) and declining policy compared to current (less good), and subsidy is still as it is today. The moderate scenario is prepared by predicting a reduced population growth rate (4.5\%) supported by policy improvements to improve performance by about $10 \%$ from previous conditions (good enough). Also, in a moderate scenario, efforts have been made to set aside about $1 \%$ of public revenue and about $25 \%$ of tourist taxes for the development of tourism matters.

The optimistic scenario is prepared with a predicted growth rate of population growth can be reduced to $4.0 \%$ supported by improvement of policy which can improve performance by about $25 \%$ from previous condition (good). In addition, in a moderate scenario, efforts have been made to set aside about $5 \%$ of public revenue and about $50 \%$ of tourist taxes for the development of tourism matters.

The simulation results of the population growth scenario and the number of tourists from 2008 to 2030 show a relatively stable growth dynamics such as the current state. Growth for each scenario is an increase with different growth trends, according to the rate of growth. The simulation results of population and tourist growth scenarios are presented in Figure 10 and Table 4.

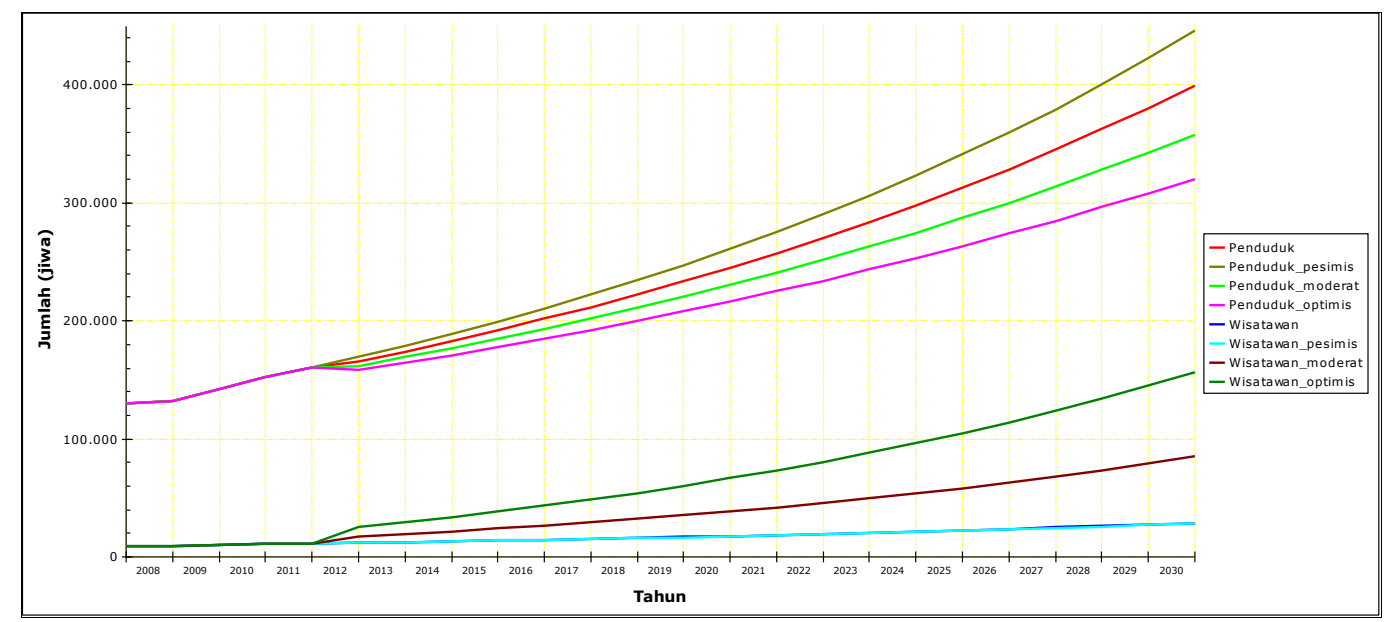

Figure 8 Simulation results of population growth scenarios and some tourists of TNBNW.

The above simulation results show population growth and the number of tourists will continue to increase from 2013 to 2030. The population in 2008 is expected to increasefrom 130,025 people to 165,949 in 2013 . The population is expected to increase 
to 380,357 by 2030 . In the pessimistic scenario, the population in 2013 is estimated at 169,937 people and will increase to 422,261 in 2030 . In the moderate scenario, the population in 2013 is estimated at 162,035 people and will increase to 342,441 in 2030. While in the optimistic scenario the population in 2013 is estimated at 158,195 people and will increase to 308,149 in 2030 . Generally, this shows that moderate and optimistic scenario requires various efforts to reduce the number of population growth that could be one cause of threat to the existence of conservation areas.

The simulation result of increasing number of tourist visit to the conservation area shows a relationship with population growth. In general, the growth pattern of the number of tourists has a proportional relationship with population growth.

The number of tourists in 2008 of 12,031 people is expected to increase to 27,576 in 2030. In the pessimistic scenario, the number of tourists in 2013 is estimated at 12,012 people and will increase to 27,246 in 2030 . In a moderate scenario, the number of tourists in 2013 is estimated at 17,621 people and will increase to 79,446 people by 2030 . While in the optimistic scenario the population in 2013 is estimated at 25,806 people and will increase to 145,215 in 2030 . In addition to being one threat to the existence of conservation areas, population growth can also be the potential and opportunities in increasing tourist visits to the conservation area.

Simulation results of public income scenarios, tourism taxes, and subsidies show a correlation with the growing number of tourists. Growth for each scenario is an increase with different growth trends, according to the rate of growth. Scenarios simulation results of community incomes, tourism taxes, and subsidies are presented in Figure 67 and Table 21.

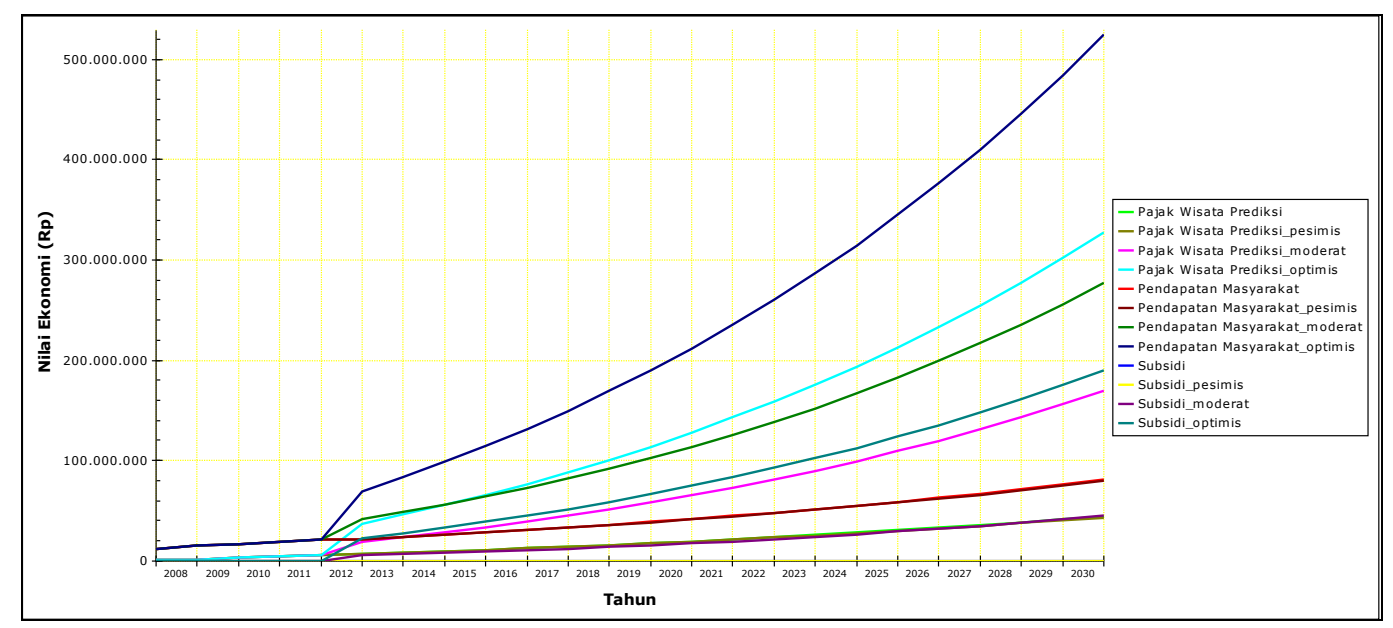

Figure 10. Scenarios simulation results of community incomes, tourism taxes, and subsidies in surrounding areas.

The simulation results show that in all scenarios, people's income and tourism taxes tend to increase due to the growing number of tourists visiting the conservation area. While subsidies on moderate and optimistic scenarios also tend to increase along with the increase in the amount of community income and tourism taxes.

Community revenues in 2008 of $\mathrm{Rp} 12,000,000$ are expected to increase to $\mathrm{Rp}$ $78,806,894$ by 2030 . In a pessimistic scenario, the community in 2013 is estimated at Rp $21,734,873$ will increase to $\mathrm{Rp} 74,662,136$ by 2030 . In a moderate scenario, the community in 2013 is estimated at $\mathrm{Rp} 41.221631$ will increase to $\mathrm{Rp} 256.020 .001$ by 
2030. While in the optimistic scenario, the community income in 2013 is estimated at Rp 69,656,421 will increase to Rp 484,520,719 in 2030.

The tourism tax in 2008 is expected to increase from $R p$ 1,250,000 to $R p 41,177,099$ by 2030. In a pessimistic scenario, community income in 2013 is estimated at $\mathrm{Rp}$ $6,649,631$ will increase to $\mathrm{Rp} 40,446,118$ in 2030 . In a moderate scenario, the community income in 2013 is estimated at Rp 19,092,821, which will increase to Rp 156,251,438 in 2030. While in the optimistic scenario, the community income in 2013 is estimated at Rp $37,249,739$ will increase to Rp 302,159,634 in 2030.

It shows that moderate and optimistic scenario requires various efforts to increase community income and tourism tax that could be one of the supporting factors in the management of tourism in conservation areas. It can be implemented by setting aside a portion of community income and tourism taxes as subsidies for various tourism development efforts in conservation areas.

New subsidized scenario simulation results are seen in moderate and optimistic scenarios. It is possible because under existing conditions and pessimistic scenarios it is assumed that there is no subsidy set aside from public income and tourist taxes. In a moderate scenario, subsidies in 2013 are estimated at Rp 5.185.421 and will increase to Rp 41.623.059 in 2030. While in the optimistic scenario, the subsidy in 2013 is estimated at Rp 22.107.690 and will increase to Rp 175.305.853 in 2030. It suggests that the increase in community incomes and tourism taxes can increase the development of tourism in conservation areas through subsidies for their management.

Simulation results of land cover change scenarios from 2008 to 2030 show a relatively stable growth dynamics such as the current state. Growth for each scenario is an increase with different growth trends, according to the rate of growth. Simulation results of population and tourist growth scenarios are presented in Figure 67 and Table 26.

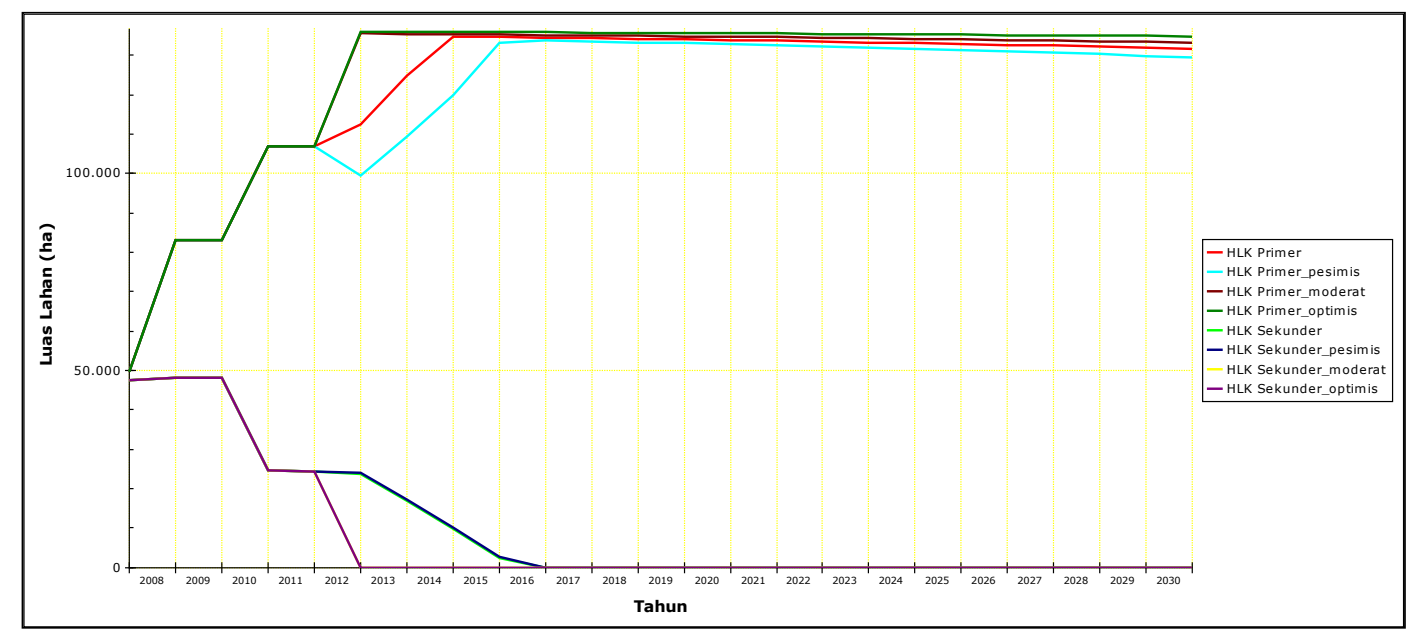

(a) Primary and secondary dry-land forests 


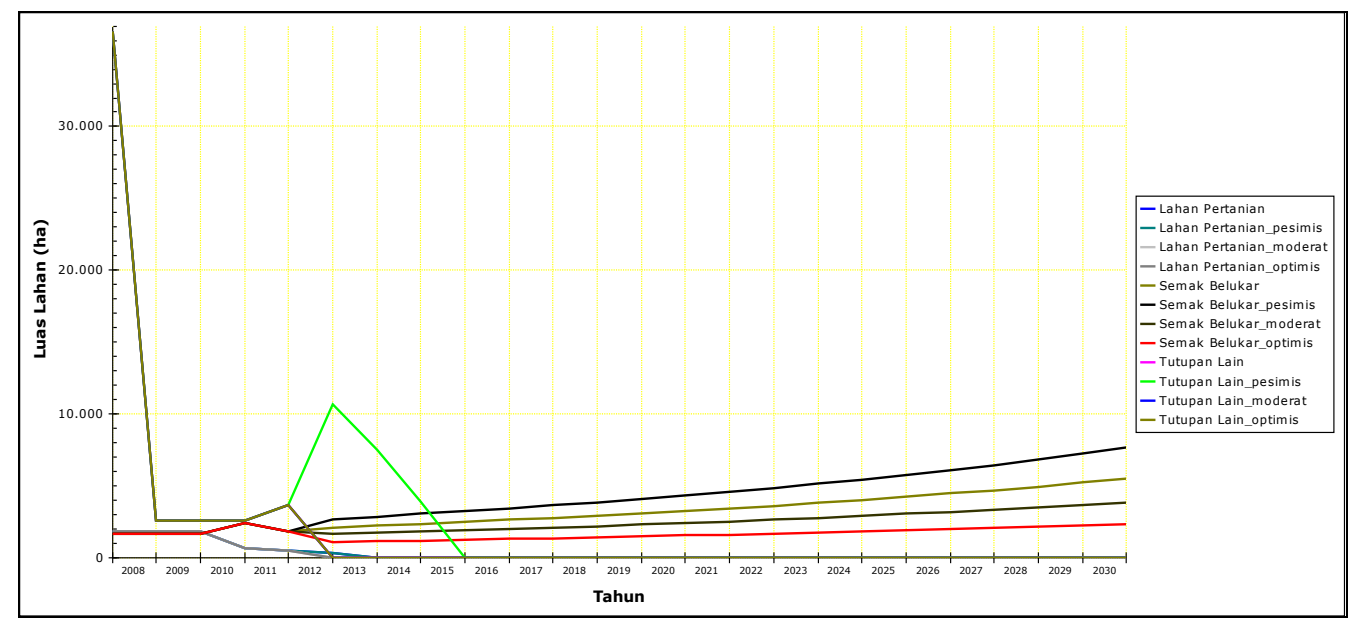

(b) Agricultural land, shrub and other covers.

Figure 9. Simulation results of land cover change scenarios in conservation areas.

The simulation results of the various scenarios above show the dynamics of land cover from 2013 to 2030 . Generally, primary dry-land forest cover and shrub show a tendency to increase coverage area. Whilst the area of secondary forest lands cover, agricultural land, and other covertends to decrease the area of land cover. In various scenarios, these three types of land cover are predicted to be replaced by primary forest cover and shrubs from 2014 to 2017.

The area of primary dry-land forest cover in 2008 of 49.561 ha is expected to increase to 131.914 ha by 2030 . In a pessimistic scenario, the area of primary dry-land forest cover in 2013 is estimated at 99.424 ha and will increase to 129.902 ha by 2030 . In a moderate scenario, the area of primary dry-land forest cover in 2013 is estimated to be 135.510 ha and will decrease slightly to 133.471 ha by 2030 . In an optimistic scenario, the area of primary dry-land forest cover in 2013 is estimated to be 136.040 ha and will slightly decrease to 134.910 ha by 2030 .

Meanwhile, the area of secondary forest land cover in the existing and pessimistic scenario is expected to be exhausted and replaced by primary dry-land and shrubs. The area of 47.445 ha of secondary dry-land forest cover in 2008 is estimated to be reduced to 2.328 ha by 2016. The area of secondary dry-land forest cover is expected to be exhausted by 2017 . In a pessimistic scenario, the area of secondary dry-land forest cover in 2013 is estimated to be 23.997 ha and will be reduced to 2.771 ha by 2016, and is expected to begin to run out in 2017. In a moderate and optimistic scenario, the area of secondary dryland forest cover has been running out since 2013.

The same is true of agricultural land, where the area of agricultural land cover will be exhausted in 2014 on the existing and pessimistic scenario, and runs out since 2013 in a moderate and optimistic scenario. The remainder of the four types of land cover is categorized as the extent of another cover. Other cover areas have the remaining area of an aggregate of four types of land cover above.

In addition to primary dry-land forest cover, shrub cover is also expected to replace secondary forest land cover and agricultural land. The shrub area of $\mathrm{x}$ ha in 2008 is expected to increase to an area of $x$ ha by 2030. In the pessimistic scenario of shrub cover in 2013, it is estimated that an area of $x$ ha will increase to $x$ ha by 2030 . In moderate scenarios, the shrub cover in 2013 is expected to cover an area of $\mathrm{x}$ ha and will increase to 
an area of $x$ ha by 2030. While in the optimistic scenario, the area of shrub cover in 2013 is estimated to cover an area of $\mathrm{x}$ ha and will increase to an area of $\mathrm{x}$ ha by 2030.

\section{CONCLUSION}

Structurally, the interacting elements in the nature tourism system, in general, is the population; some tourist visitors; community income; income tax; land use/forest cover and development policy direction. Based on these elements, sub-model identification is classified into a sub-model of socio-economic and policy and environmental models. The dynamics that occur in the socioeconomic sub-model are if there is an increase in the population will result in increased number of tourist visitors which also affects the increase in the amount of public income and taxes. The dynamics of the policy and environmental sub-model is shown by the increase of population, the amount of income and the number of tourist visitors in 2008 until 2013 can result in the decrease of the area of secondary forest cover where the location as a place of natural tourist attraction in TNBNW.

\section{REFERENCES}

Dodds R, Butler R. (2010). Barriers To Implementing Sustainable Tourism Policy In Mass Tourism Destinations. Tourismos: an international multidisciplinary journal of tourism, 5 (1), spring, 35-53 35

Hartrisari. (2007). Sintem Dinamik: Konsep Sistem dan Pemodelan untuk Industri dan Lingkungan. Southeast Asian Regional Centre for Tropical Biology (BIOTROP)

Marimin. (2008). Teknik dan Aplikasi Pengambilan Keputusan Kriteria Majemuk. PT. Gramendia, Jakarta.

Maani K.E. danCavana R.Y. (2007). System Thinking, System Dynamics. Managing Change and Complexity.Pearson Education New Zealand.

Purnomo H. (2012). Pemodelan dan Simulasi untuk Pengelolaan adaftif Sumberdaya Alam dan Lingkungan. IPB Press.

Sunkar A. (2008). "Sustainability In Karst Resources Management: The Case Of The Gunung Sewu In Java". A thesis submitted in fulfilment of the requirements for the degree of Doctor of Philosophy The University of Auckland, 2008 